\title{
XXXXI. On valency, validity, and residual affinity
}

\author{
J.F. Heyes M.A. F.C.S. F.R.G.S.
}

To cite this article: J.F. Heyes M.A. F.C.S. F.R.G.S. (1888) XXXXI. On valency, validity, and residual affinity , Philosophical Magazine Series 5, 25:155, 297-313, DOI: $10.1080 / 14786448808628190$

To link to this article: http://dx.doi.org/10.1080/14786448808628190

册 Published online: 29 Apr 2009.

Submit your article to this journal $\pi$

Џ Article views: 4

Q View related articles $\sqsubset$ 
XXXXI. On Valency, Validity, and Residual Affinity. By J. F. Heyes, M.A., F.C.S., F.R.G.S., of Magdalen College, Oxford.*

THE timely paper by Professor Armstrong, entitled "A 1 Note on Valency, especially as defined by Helmholtz," $\dagger$ induces me to publish my paper on the tetravalency of oxygen, and to offer some remarks on his paper in the hope that both, so happily coincident and containing independent views and suggestions, will do something to bring forward the consideration of the problems of Valency which are so essentially characteristic of the present state of Chemical Philosophy. Raw material abounds. It is now surely more essential for chemists to study the inner mechanism, so to speak, of the chemical molecule both in the interrelationships of the parts and the forces concerned than to discover, say, more oxides of manganese when we have already too many. Especially would I venture to direct attention to the paradox which now confronts us in the contrast existing, on the one hand, between so many of the complex organic molecules whose "constitution" we know, or at any rate whose interatomic relationships are regular and certain, even to a degree of prediction within remarkable limits, and, on the other, between so many simple inorganic molecules. Why, in fact, should "the constitution" of complex $\mathrm{C}_{x} \mathrm{H}_{y} \mathrm{O}_{z}$ or $\mathrm{C}_{p} \mathrm{H}_{q} \mathrm{O}_{r} \mathrm{~N}_{s}$ be known, and simple $\mathrm{N}_{x} \mathrm{O}_{y}$ remain a puzzle, which tends to make many chemists write the old unitary formula in despair and betake themselves to the seductive studies of molecular physics?

In my previous paper $\ddagger$ some probable causes of confusion have been discussed which have led to the different views held on valency, but the problem is one for the immediate future. Prof. Armstrong draws our attention to the electriccharge theory of valency-using that term, it is presumed, in the sense of a property of the atom which used to be called atomicity. My paper suggested that valency was primarily a number or numbers, the measure of something whose real character and denomination science is still seeking, but nevertheless a something towards whose perception electrical, thermal, and atomic mass ratio constants are rapidly converging. The number and the thing itself should not be confounded. But our fundamental standpoint in valency is that

* Communicated by the Author.

$\dagger$ Phil. Mag. pp. 21-30 of the present volume.

$\ddagger$ Phil. Mag. pp. 221-237 of the present volume. 
of integers and not decimal residues*. It is only in respect to our standard reference gas-molecule $\mathrm{HCl}$ ', where hydrogen and chlorine are said to be monovalent, that the valencies of oxygen and nitrogen atoms in the comparable molecules can be said to be divalent and trivalent, i.e. dyads and triads $\dagger$. In face of the enormous difficulties presented by "molecular compounds," we are apt to forget that all chemicals consist of chiefly heterogeneous and rarely of homogeneous compound molecules; and a rush has, as it were, been made to dispose of them by giving numerous valencies to either the non-metallic or the metallic atom supposed to dominate all the rest. Thus, Wurtz latterly assigned different valencies in different compounds to

$\begin{array}{lllllllll}\text { Nitrogen : } & 1 & 2 & 3 & & 5 & & & \\ \text { Halogens : : } & 1 & & 3 & 4 & 5 & & 7 & \\ \text { Uranium . : } & & 2 & 3 & & 5 & & & \\ \text { Vanadium : : } & & & 3 & 4 & 5 & & & \\ \text { Manganes : } & & 2 & & & & 6 & 7 & \\ \text { Osmium \&c. : } & & 2 & & 4 & & 6 & & 8\end{array}$

Analogous high valencies have been suggested by Prof. Williamson and others for many rare metals of high atomic weights; but in this case the halogens were taken as monads. Both views have the same underlying principle. In the one case a Peter dominates the Pauls, in the other a Paul dominates the Peters. Both involve what I have pictured as the maypole theory. Oxygen atoms dance round nitrogen or

* The logical alternative is, I find, well put in a remarkable paper on Atomic Valency by Prof. Pickering (Journ. Chem. Soc. 1886):- "The valency of hydrogen being 1 , that of oxygen will be represented by some number slightly smaller than 2, say 1.98; a compound of these two elements will possess a residual valency of only 0.02 , and will therefore be sufficiently saturated to be perfectly stable. It may be represented thus : $\left(\mathrm{H}_{2} \mathrm{O}\right)+0^{\circ} 02$." He therefore treats "valencies" as "not whole numbers," but "similar to most other physical constants, e. g. atomic weights, specific weights."

$\dagger$ A distinction should be drawn between this provisional definition of a trivalent element and the proposition advanced in Prof. Armstrong's paper (page 24) that " the gasefiable hydrogen compounds are the only compounds available for the direct determination of valency." Undoubtedly our present standard of reference is $\mathrm{H}^{\prime} \mathrm{Cl}^{\prime}$ as a comparable molecular formula; but it seems only fair, on the principle of reciprocity, not to leave the valency of metals to turn upon their few compounds or alloys with another gaseous metal hydrogen (see my former paper, page 225). The caution that, in the case of the halides, $\mathrm{XH}_{n}$ does not necessarily involve a valency of $\mathrm{X}^{n}$ is most important, and will, it is to be hoped, lead to some investigations into the existence and chemical habitudes of nuclei and ring-formulø of nitrogen or nitrogen and carbon, chlorine, iodine, oxygen, \&c. 
chlorine in the one case, democratic chlorine or oxygen atoms dance round a rare and monarchial metallic atom in the other. This is illustrated by Wurtz's arguments in support of $\mathrm{NH}_{4} \mathrm{Cl}$ as ${ }_{\mathrm{N}}^{\mathrm{H}}>_{\mathrm{H}}^{\mathrm{H}}$; and the now departure is indicated by what Prof. Armstrong calls his first "apple of disoord" when he disputes the evidence usually taken to justify the analogous domination of $\mathrm{N}$ in $\mathrm{Me}_{4} \mathrm{NI}$. I have been independently led to similar conclusions, and would write the constitutional formula as

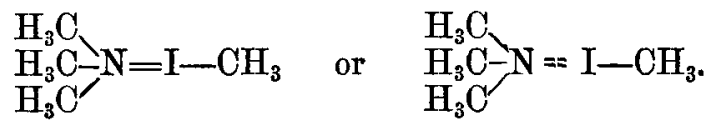

The peck-lines are simply meant to show that the point for discussion is the valency or validity of the nitrogen and iodine atoms. Those who accept $\mathrm{NMe}_{4} \mathrm{I}$ as not a molecular compound usually assume (1) that $\mathrm{N}$ is pentavalent, (2) that I is monovalent, (3) that there are four methyl groupings (or other $\mathrm{R}^{\prime}$ ) directly and equally intimately associated with the nitrogen atom. The formula given simply asserts:-(1) That the chemical evidence favours a belief in the direct association of only three of the four methyls; (2) That in whatever sense the nitrogen atom is pentad not triad, in that same sense the iodine atom is interdependently triad not monad. If the nitrogen is pentavalent here, the iodine atom is also trivalent. But in order that the dispute may be fought out with the less risk of misunderstanding, my previous paper proposed (1) that the rarer or disputed valency may be referred to as validity, and (2) the latin prefixes and (3) roman numerals be exclusively used for this latter disputed number. Anything that tends to order and method in our present notation is at least worth consideration. Now nobody disputes that nitrogen is trivalent. Let us, then, in this and in other well-recognized cases keep uniformly to the greek prefix and symbolize a trivalent nitrogen atom as $\mathrm{N}^{\prime \prime \prime}$, reserving the symbol $\mathrm{N}^{v}$ for the disputed quinquivalid nitrogen in such compounds as those under consideration whenever there is likely to be ambiguity. The first formula would thus assert that iodine was therein trivalent, the second that it is tervalid; but that whether validity is a property (electrical wholly or in part), a function of the atom of the same chemical intensity as that relatively suggested by the numbers $1,2,3$, already defined, and known 
as valency or atomicity, is left open for investigation and discussion. It may also be useful to adopt the word adicity, long ago proposed by Prof. Odling as comprehending both valency and validity*. Thus it is convenient to say that the adicity of oxygen is 2 or 4, that oxygen is usually divalent, but in some cases quadrivalid, if not actually tetravalent, leaving questions of molecular compounds not entirely closed on the chemical side, especially in the case of all $\mathrm{X} . y \mathrm{H}_{2} \mathrm{O}$ "compounds." To take another example; in the case of the notorious $\mathrm{CO}$ molecule, if the oxygen atom is not there tetravalent the carbon atom is bivalid. The "molecular compounds" dispute does not here arise. On the other hand, in such formulæ as $\mathrm{AgKI}_{2}$ and $\mathrm{AgI}$. KI sides are taken. On the former side we should write $A g-I=I-K$; whereas $\mathrm{Ag}-\mathrm{I}=\mathrm{I}-\mathrm{K}$ would suggest the controversy :-Is iodine here trivalent or is it tervalid in either some integral sense akin to atomicity or in the sense suggested by the working hypothesis of " residual affinity" ?

There has undoubtedly been great ambiguity of expressions hitherto in this matter. Thus, whilst Wurtz admitted that " $\mathrm{NH}_{4} \mathrm{Cl}$ belongs to the type $\mathrm{NX}_{5}$ ", and held " generally and implicitly that the chlorine and the four atoms of hydrogen are united individually to the pentavalent nitrogen," he at the same time gave as two reasons why $\mathrm{HCl}$ and $\mathrm{NH}_{3}$ can unite:-(i.) "the atoms uniting are in possession of a residue of affinity;" (ii.) "the atoms of nitrogen can admit into their sphere of action a fourth atom of hydrogen and an atom of chlorine" (Atomic Theory, 1880, transl. p. 247). He went on to deprecate "creating and employing secondary hypotheses." "Why should we graft upon this atomic hypothesis a second, a special attraction which in a completed combination is exercised by one molecule upon another ?" The italics are mine, and they should be compared with the views be expresses later on and the cases of residual affinity as Prof. Armstrong employs the phrase. In $\mathrm{PCl}_{5}$ Wurtz held that "two atoms of chlorine were retained more loosely than the other three"; but the retaining force was "most naturally" attributed to residence in the atoms themselves; the $\mathrm{P}$ atom in $\mathrm{PX}_{5}$ "can retain a residue of energy capable of fixing new atoms and of developing, if we may be allowed the expression, supplementary atomicities." These statements are of great

* I note that Prof. Armstrong uses the word (p. 28) in "pentadicity of phosphorus," apparently in the more open sense of validity. As Prof. Odling used the word cautiously with reference to valency it may be convenient to retain it in the inclusive sense of $\mathbf{P}^{\prime \prime \prime}$ and $\mathrm{P}^{\mathrm{v}}$. 
historic interest in the discussion, though scarcely consistent. Prof. Armstrong more logically inclines to the acceptance of only one number for valency concerned with what may be called chemical affinity of the first magnitude, and suggests that besides this affinity proper (say a trivalent atomic charge) there are residual affinities in play which probably account for molecular compounds and aggregates. Curiously enough he would, in many cases, thus place among "molecular compounds" many hitherto generally recognized "chemical molecules." (Chemists will be loth to part with these. It is, as it were, taking our friends' dogs to the dog's home when the street dogs really demand our attention. He supposes that $\mathrm{NMe}_{4} \mathrm{I}$ is "the molecular compound" (tetramethyl ammonium iodide) caused by the union of the two molecules $\mathrm{Me}_{3} \mathrm{~N}$ and IMe determined by the "residual affinities" of the $\mathrm{N}$ and I atoms represented thus :-

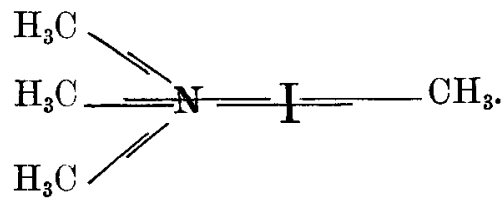

Whilst agreeing with the associations thus indicated, I propose that the $\mathrm{N}$ and $\mathrm{I}$ atoms be named in such cases "quinquivalid" and "tervalid" respectively,

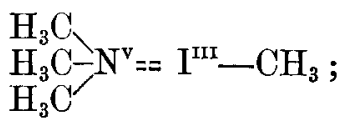

leaving it open for future research and discussion to determine the exact nature and limits of validity and valency, since we cannot at present commit ourselves to any partial theory, say either that of Helmholtz or of J.J. Thomson. Indeed we have also as chemists to keep an open mind on the sphere and vortex-ring hypotheses of an atom *. It may, however,

* Professor Armstrong says, "It may well be argued that we have no reason to assume that nitrogen is pentad in the ammonium compounds, or phosphorus pentad in the phosphonium compounds, or sulphur tetrad in the sulphine compounds" (p. 24). My proposal involves the idea that nitrogen is pentad in whatever sense chlorine is triad in $\mathrm{NH}_{4} \mathrm{Cl}$ taken as $\mathrm{H}_{3} \mathrm{~N}==\mathrm{Cl}-\mathrm{H}$, there being no reason to assume that the four atoms of hydrogen are directly associated with the nitrogen. Similarly for phosphonium compounds; but for other reasons $(e . g$. the evidence of the phosphinic acids, of $\mathrm{PO}\left(\mathrm{C}_{2} \mathrm{H}_{5}\right)_{3}, \mathrm{PO}\left(\mathrm{O}_{6} \mathrm{H}_{5}\right)_{3}$, and other bodies) the pentavalency of phosphorus seems much better established than that of nitrogen. This observation tallys with the recognition of an "allotropic form" of 
be convenient in electrolysis investigations, for instance, when there is no ambiguity, to use the phrase "residual affinity," and the appropriateness of the analogy to "residual charge" of a leyden jar is obvious. But it seems hard to place so many of the compounds mentioned in my former paper, and even $\mathrm{PCl}_{5}$ or $\mathrm{N}\left(\mathrm{C}_{2} \mathrm{H}_{5}\right)_{4} \mathrm{OH}$, outside the pale of honest "atomic" compounds-i.e. chemical molecules-and alongside the innumerable hydrates which molecular, or pro-

phosphorus not yet known in the case of nitrogen. The alleged cases of

$$
\left.\left.\underset{\mathrm{CH}_{3}}{\mathrm{CH}_{3}}\right\} \mathrm{~S}+\mathrm{C}_{2} \mathrm{H}_{8} \mathrm{I} \text { and of }{ }_{\mathrm{OH}_{3}}^{\mathrm{C}_{3} \mathrm{H}_{5}}\right\} \mathrm{S}+\mathrm{CH}_{3} \mathrm{I}
$$

giving distinct compounds (p. 27) of $\mathrm{S}\left\{\begin{array}{l}\mathrm{C}_{2} \mathrm{H}_{8} \\ \mathrm{CH}_{3} \\ \mathrm{CH}_{3}\end{array}\right.$ is also interesting from the possibility of iodine being trivalent or at least tervalid. Then there would be

$$
\underset{\mathrm{H}_{3}}{\mathrm{H}_{3} \mathrm{O}}>\mathrm{S}=\mathrm{I}-\mathrm{C}_{2} \mathrm{H}_{5} \text { and } \underset{\mathrm{H}_{3}}{\mathrm{H}_{5}} \mathrm{C}_{2} \backslash \mathrm{S}==\mathrm{ICH}_{3} .
$$

Sulphur is at least tetravalent in whatever sense iodine is trivalent. But, even assuming $\mathrm{S}^{\mathrm{vv}}\left\{\begin{array}{l}\mathrm{C}_{2} \mathrm{H}_{5} \\ \mathrm{CH}_{3} \\ \mathrm{CH}_{3} \\ \mathrm{I}\end{array}\right.$ and the "equal value" of the "affinities" of the sulphur atom, we might expect a case of physical isomerism in<smiles>[3H][Si](C)(CC)CCC</smiles>

where the methyl radicals hold ortho and meta "pcsitions," as it were, even on the maypole hypothesis. Since writing I find striking statements by Professor Tilden on the trivalency of iodine written in 1876. On page 181 of his 'Introduction to Chemical Philosophy' (first edition) he even gave a closed-ring formula for $\mathrm{KHg}_{\mathrm{3}}$ as $\mathrm{K}-\mathrm{I} / \mathrm{I}_{\mathrm{I}} / \mathrm{Hg}$, pointing out

that although " many chemists regard such compounds as formed by the union of entire molecules of the constituent salts combined together by some sort of adhesion differing from ordinary chemical affinity," yet " If they do they might naturally be expected to exhibit something of the appearance and external characters of their proximate constituents." He also considered the idea of "two extra units of combining power" for oxygen "not wholly preposterous," and sketched crystallized $\mathrm{ZnSO}_{4} \mathrm{OH}_{2} .6 \mathrm{OH}_{2}$ with "four bond" oxygen atoms throughout. This was, however, with a view to diminish the number of " molecular combinations," which in a sense it is now proposed to increase. There is much logic and tempting simplicity in the view that an atom is always $n$-valent, and that conflicting puzzles are "molecular," not "atomic," but this logical view seems intimately connected with the idea that the atom of $\mathrm{N}$, for example, was born a manufactured article with three hooks, or bopds. 
bably in many cases molar, physico-chemical experiments are forcing upon bewildered chemists. We must at any rate leave many of them in quarantine for some time to come. And, considering that the mortal chemist will always have to do almost all his work at the bottom of a varyingly moist aerial ocean, it is surely time that a protest was made against the claims for admission to the chemical record of so-called "new" bodies, which are simply more or less moist than the ordinary substance. Messrs. Carnelley and Walker bave recently carefully* adduced instances of these chemical impostures. It is quite refreshing to find among them an honest hydrate like $\mathrm{Ce}(\mathrm{OH})_{4}$ which can stand $600^{\circ} f$; but surely the line should be drawn at the temperature of hot water. In other cases of alleged "molecular compounds" some tangible chemical evidence should be required of their existence, or at least of the chemical homogeneity of the material or watered substance which is said to contain them. At the most, then, the so-called "silver hydrate" should be formulated as $\mathrm{Ag}-\mathrm{O}-\mathrm{Ag}$ and not as $\mathrm{AgOH}$. To use the latter and to use $\mathrm{HCl}$ for ordinary "hydrochloric acid" is to strain out the gnat and swallow the camel. The fact probably is that it has become popular in preference to $\mathrm{Ag}_{2} \mathrm{O}+\mathrm{OH}_{2}$, because of the frequent replacement of $\mathrm{Cl}$ by $\mathrm{OH}$ through its use in organic chemistry. Even in using the formula $\mathrm{HCl}$ conjointly with $\mathrm{NH}_{4}(\mathrm{OH})$, we are guilty of going against the weight of evidence, probably influenced, as Prof. Armstrong (rightly as it seems to me $f$ ) suspects, by the "ammonium" theory. Liquid hydrochloric "acid" does not dissolve a single metal, except perhaps aluminium. And it may be asked, Why should a liquid metallic chloride be expected to do so? The common equation $\mathrm{Zn}+2 \mathrm{HCl}=\mathrm{ZnCl}_{2}+\mathrm{H}_{2}$ is, of course, quite untrue. It is even more objectionable than the misleading sheetanchor of so many textbooks: $\mathrm{Zn}+\mathrm{SO}_{4} \mathrm{H}_{2}=\mathrm{ZnSO}_{4}+\mathrm{H}_{2}$. In "hydrochloric acid" the chlorine is probably tervalid and the

* Journ. Chem. Soc. Jan. 1888, p. 59.

+ This is probably connected with the quite exceptional volatility of osmium oxide. The metallic atom is possibly inside an oxygen nucleus, as it were,

$\ddagger$ This is instanced in the ingenious $\left[\mathrm{NH}_{2}\left(\mathrm{Hg}_{2}\right)^{\prime \prime}\right]^{\prime}$ formulæ given in the case of mercur-ammonium and other difficult compounds. Of course if $\mathrm{Cl}=\mathrm{Hg}$ be admitted for calomel, $\mathrm{NH}_{\mathrm{Cl}=\mathrm{Hg}} \mathrm{Hg}^{\prime \prime}$ follows as a corollary. 
oxygen quadrivalid, just as in the case of "ammonium hydrate."<smiles>O[HgH]</smiles><smiles>O[NH+]=[V]</smiles>

Probably Professor Armstrong would agree that chlorine as well as oxygen is here possessed of "residual affinity." But, adopting Thomsen's formula $\mathrm{H}_{3} \mathrm{ClO}$, the acid liquid would be $\mathrm{HCl}=\mathrm{OH}_{2}$. The more open view, $\mathrm{HCl}==\mathrm{OH}_{2}$, is then fairly warranted. It is this chemical unit which doubtless is active in effecting the hydrolysis of the alcoholic cyanides $\mathrm{R}^{\prime} \mathrm{CN}$, which neither water alone nor liquefied hydrogen chloride, $\mathrm{HCl}$, does effect. The suggestion that $\mathrm{TeCl}_{4}$ does not prove the tetravalency of tellurium is particularly interesting, since the suggestions of

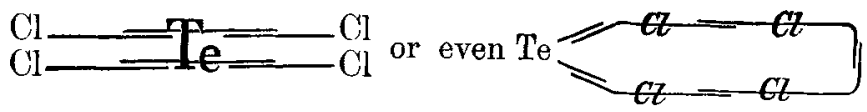

are likely to lead to new developments in the discussion of the valency of the inorganic elements. The suggestion, on valency lines, had been made in my former paper, in the case for instance of $\mathrm{TlI}_{3}$, as<smiles>[Al]1[In]I=I1</smiles>

and the fact that two somewhat different lines of thought suggest these "closed-chain" molecules will, it is to be hoped, stimulate the discussion on valency. Undoubtedly the haloid compounds (except in the case of hydrocarbon derivatives) must be carefully examined before it can be claimed that a $\mathrm{XCl}_{n}$ "proves " the $n$-valent nature of $\mathrm{X}$. This is especially the case with non-volatile chlorides, and is well exemplified by $\mathrm{PtCl}_{4}$. In view of its chemical habitudes it is not easy for me to believe in the symmetrical arrangement

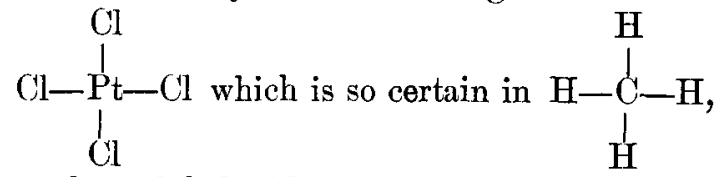

or even to be satisfied with

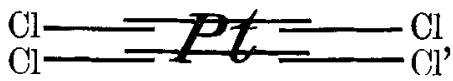

which leaves us with Hobson's choice.

Platinum tetrachloride has the properties of an asymmetrical chloride to a much greater degree than $\mathrm{PCl}_{5}$. It seems likely 
that the platinum is divalent, and yet that the peculiarity of the chlorine atoms-their residual affinity, validity, or even valency - enables $\mathrm{Cl}_{2} \mathrm{Pt}$ to play the part of an. unsaturated radical, but not because $\mathrm{Pt}$ is necessarily tetravalent. On this hypothesis I would write $\mathrm{PtCl}_{4}$ as

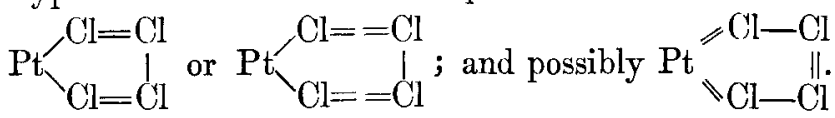

This indicates the chemical asymmetry of the two chlorine atoms. Either heat or free iodine removes the two remoter atoms (or, say, more accessible vortex-rings), giving in the latter case red crystals of $\mathrm{PtCl}_{2} \mathrm{I}_{2}$, i. e. $\mathrm{Pt}^{\prime}{ }_{\mathrm{Cl}=1}^{\prime}=1$. Platinum is therefore not octavalent in $\mathrm{H}_{2} \mathrm{PtCl}_{6}$, and probably not even tetravalent. The existence of the so-called molecular compound is simply due to the peculiarities of the chlorine, as suggested by

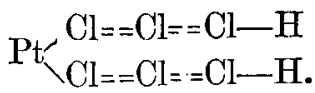

This is probably the type of the characteristic compounds of the platinum and palladium triplets, $\mathrm{Rh}, \mathrm{Ru}, \mathrm{Pd}$ and $\mathrm{Ir}, \mathrm{Os}, \mathrm{Pt}$. The double chlorides are asymmetrical. The same idea applies to the characteristic $\mathrm{R}_{2}^{\prime} \mathrm{MF}_{6}$ of the $\mathrm{Ti}, \mathrm{Zr}$, Th and $\mathrm{Si}, \mathrm{Ge}, \mathrm{Sn}$ triplets. In cases where the chlorine atoms are symmetrical we often find an equal number of molecules associated by the mysterious $\operatorname{dot}(\cdot)$. The type is $\mathrm{XCl}_{n} \cdot n \mathrm{M}$ where $\mathrm{M}$ is $==\mathrm{ClK}$, $==\mathrm{NH}_{3},==\mathrm{CO}, \mathrm{KCN}==$ and such like. Thus there is not only $\mathrm{TlCl}_{3}$ and $\mathrm{TlCl}$, but also $\mathrm{TlCl}_{3} .3 \mathrm{ClK}$.

Validity is inter alia conditioned by temperature, and a temperature of $200^{\circ}$ resolves either $\mathrm{H}_{2} \mathrm{PtCl}_{6}$ or $\mathrm{PtCl}_{4}$ into $\mathrm{PtCl}_{2}$. That $\mathrm{Pt}$ is divalent in $\mathrm{K}_{2} \mathrm{Pt}(\mathrm{CN})_{4}$ seems to be indicated by its formations from either $\mathrm{PtCl}_{2}$ or $\mathrm{PtCl}_{4}$. Light will probably also be thrown upon the difficulties which beset attempts to give constitutional formulæ to the numerous isomeric or even metameric resultants between ammonia and chlorides. Their existence would appear to be due to this validity of the nitrogen and chlorine. For instance, of the two different substances formulated, $\mathrm{PdCl}_{2} \mathrm{~N}_{2} \mathrm{H}_{6}, \mathrm{Pd}$ being a well-defined dyad, the red one yields $\mathrm{NH}_{3}$ easily, and the yellow one gives no $\mathrm{NH}_{3}$ on treatment with $\mathrm{KHO}$, but is the dichloride of a divalent radical, $\left(\mathrm{PdN}_{2} \mathrm{H}_{6}\right)$, , whose oxide and whose alkaline hydrate are known. In this yellow compound the chlorine is probably monovalent or the nitrogen pentavalent,

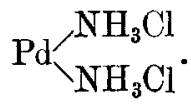


But in the red compound the chlorine is trivalent, or at least tervalid, and the nitrogen quinquivalid,

$$
\operatorname{Pd} \backslash \begin{aligned}
& \mathrm{Cl}=\mathrm{NH}_{3} \\
& \mathrm{Cl}=\mathrm{NH}_{3}
\end{aligned}
$$

It will also be noticed that both $\mathrm{PtCl}_{2}$ and $\mathrm{PtCl}_{4}$ are, as the phrase goes, " unsaturated compounds." This could not well be the case if the valency of the platinum were altered in $\mathrm{PtCl}_{4}$; and they must therefore be due to the tervalidity of the chlorine, rather than the tetravalency, or to the residual affinity of the platinum. Thus, $\mathrm{PtCl}_{2}$ yields $\left(\mathrm{PtCl}_{2} \mathrm{P}\right) \mathrm{Cl}_{3}$, $\mathrm{PtCl}_{2} \mathrm{P}(\mathrm{OH})_{3}$, and $\mathrm{PtCl}_{2} 2 \mathrm{PCl}_{3}$, and $\mathrm{PtCl}_{2} \mathrm{P}_{2}(\mathrm{OH})_{6}$. In such cases, apparently, the higher valencies must be attributed to the non-metallic elements. The three compounds,

$$
\begin{aligned}
& \mathrm{PtCl}_{2} \cdot \mathrm{OC}, \\
& \mathrm{PtCl}_{2} \cdot 2 \mathrm{OC}, \\
& \mathrm{PtCl}_{2} \cdot 3 \mathrm{OC},
\end{aligned}
$$

are well worthy of consideration. It is at least obvious that the supposed dominant valency of the $\mathrm{Pt}$ is not concerned, but that the tervalidity of chlorine and the quadrivalidity of oxygen most probably are. And if we remove the so-called but very doubtful "polyad," Pt and examine the following series*, this will be still more apparent:

$$
\begin{aligned}
& \mathrm{NH}_{3} \mathrm{O} \text {. } \mathrm{ClH} \text {, } \\
& \mathrm{NH}_{3} \mathrm{O} \text {. 2 } \mathrm{ClH} \text {, } \\
& \mathrm{NH}_{3} \mathrm{O} \text {. } 3 \mathrm{ClH} \text {. }
\end{aligned}
$$

Certainly such a series suggests an analogy to the residual charge of a leyden jar, especially when we bear in mind Maxwell's observation that a dielectric composed of strata of different sorts gives the residual effect, although none of the substances alone do so.

These examples must suffice to show the meaning which may be provisionally attached to the conception of validity, with the following general results:-

(1) Very high and shifting valencies for the elements are improbable and unnecessary.

* Another striking set of triplets has just been discovered by Moissan (French Academy of Sciences, Feb. 20, 1888),

$$
\begin{aligned}
& \mathrm{KF} . \mathrm{FH}, \\
& \mathrm{KF} .2 \mathrm{FH} \text {, } \\
& \mathrm{KF} .3 \mathrm{FH} \text {. }
\end{aligned}
$$

Fluorine is indeed clearly tervalid, to say the least; and its very isolation by Moissan seems due to the combination $\mathrm{K}-\mathrm{F}=\mathrm{FH}$ or $\mathrm{K}-\mathrm{F}==\mathrm{FH}$. 
(2) The existence of the so-called molecular compounds is due to the validity or varying valency of the non-metallic radicals, certainly not, as a rule, to the very high validity of the metallic atom. Thus the great difficulty experienced in "washing" certain precipitated oxides free from potash is, I take it, due to the validity of oxygen. And in spinelle, $\mathrm{Al}_{2} \mathrm{O}_{3} \cdot \mathrm{MgO}$, the tetravalent oxygen makes it probably

$$
\begin{aligned}
& \mathrm{O}=\mathrm{Al} \\
& \mathrm{O}=\mathrm{Al}
\end{aligned}>\mathrm{O}=\mathrm{O}=\mathrm{Mg} .
$$

(3) In particular, the numerous grades of bodies containing $\mathrm{H}_{2} \mathrm{O}$ is due to the tetravalency (or quadrivalidity) of oxygen conditionally stimulated in some unknown way (say, to a change of vibration-period or to a development of residual charge) by chemical proximity to other non-metallic or negative atom or atoms.

(4) So-called catalytic change is often, if not always, due to this development or existence of validity. This is seen in the behaviour of hydrochloric acid as contrasted with liquid hydrogen chloride.

(5) So-called polymeric changes in many cases, e.g.

$$
\mathrm{H}_{3} \mathrm{C}_{3} \mathrm{~N}_{3} \mathrm{O}_{3} \text { and para-aldehyd, } \mathrm{CH}_{3} \mathrm{CH} . \mathrm{O}^{\prime} \mathrm{OCH} . \mathrm{CH}_{3} \text {, }
$$

are similarly often due to the tetravalency of oxygen. These seem to be perfectly analogous to the cases of allotropy.

(6) In such cases we must be prepared to extend the idea of nucleus hitherto confined to carbon (and extended on unsatisfactory evidence to several of the metals*) to a chlorine nucleus, an oxygen nucleus, \&c. The formula

$$
\begin{aligned}
\mathrm{Cl} & ==\mathrm{Cl} \\
\mathrm{Al}^{\prime}-\mathrm{Cl} & ==\mathrm{Cl}-\mathrm{Al} \\
\mathrm{Cl} & ==\mathrm{Cl}^{\prime}
\end{aligned}
$$

is at least as probable as

$$
\underset{\mathrm{Al}^{\mathrm{rv}} \mathrm{Cl}_{3}}{\mathrm{Al}^{\mathrm{IV}} \mathrm{Cl}_{3}}
$$

* Of the numerous cases usually instanced. that of tin seems to me alone good. The evidence of $\mathrm{Sn}_{2} \mathrm{Et}_{6}$ is strongly in favour of $\mathrm{SnEt}_{3}$; whereas $\mathrm{Sn}_{2} \mathrm{Cl}_{4}$ at low temperatures is ambiguous, and probably

$$
\mathrm{Sn}\langle\mathrm{Cl}=\mathrm{Cl}=\mathrm{Cl}\rangle \mathrm{Sn}
$$


and removes the difficulties which have been raised as to the doubtful trivalent character of aluminium. It certainly turns the scale in favour of the questioned $\mathrm{Al}\left(\mathrm{CH}_{3}\right)_{3}$, and leaves $\mathrm{Al}$ trivalent, as its place in the periodic system emphatically requires. So striking a chemical substance as the Greenland mineral cryolite, $\mathrm{Na}_{3} \mathrm{AlF}_{6}$, has hitherto been between the Scylla of the old dot formula, $\mathrm{AlF}_{3} .3 \mathrm{NaF}$, and the Charybdis of nonad or enneavalent aluminium. But it is difficult to resist the conclusion that fluorine is here trivalent,

$$
\begin{aligned}
\mathrm{F} & =\mathrm{FNa} \\
\mathrm{Al}-\mathrm{F} & =\mathrm{FNa} . \\
\mathrm{F} & =\mathrm{FNa}
\end{aligned}
$$

In the case of other double fluorides it may be that certain of the atoms are in these circumstances trivalent, e.g. in

$$
\mathrm{NbF}_{5} .2 \mathrm{KF} \text { as } \begin{aligned}
& \mathrm{F}-\mathrm{Nb}^{\prime} \mathrm{F}=\mathrm{FK} \\
& \mathrm{F}^{\prime}
\end{aligned},
$$

or

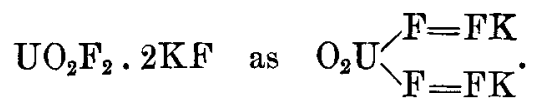

It scarcely seems to follow that two out of the five $\mathrm{F}$ atoms in $\mathrm{NbF}_{5}$ are not "chemically equal." The questions of "validity," "residual aflinity," \&c. concern the FK or F Na connexion. These ideas at least seem worth taking as a working hypothesis.

(7) Although it is premature to generalize, it is well worthy of attention that temperature is a function of validity, very often, to say the least, in the direction of change, whether of degree only or not, from validity to valency, i.e. to the smaller number. The analogy between polymerism and allotropy then seems to be as close as possible. A discussion of the following parallels would exemplify this idea:-

\begin{tabular}{ll}
\multicolumn{1}{r}{ Hotter. } & Colder. \\
$\mathrm{O}_{2}$ & $\mathrm{O}_{3}$ \\
$\mathrm{~S}_{2}$ & $\mathrm{~S}_{6}$ \\
$\mathrm{HF}$ & $\mathrm{H}_{2} \mathrm{~F}_{2}$ \\
$\mathrm{C}_{2} \mathrm{~N}_{2}$ & $\mathrm{C}_{6} \mathrm{~N}_{6}$ \\
$\mathrm{C}_{2} \mathrm{H}_{2}$ & $\mathrm{C}_{6} \mathrm{H}_{6}$ \\
$\mathrm{P}_{4}$ & $\mathrm{P}_{x}$ \\
$\mathrm{CO}$ & $\mathrm{CO}_{2}$ \\
$\mathrm{NO}$ & $\mathrm{N}_{2} \mathrm{O}_{4}$ \\
$\mathrm{~K}_{2} \mathrm{O}$ & $\mathrm{K}_{2} \mathrm{O}_{4}$ \\
$\mathrm{AuI}$ & $\mathrm{AuI}_{3}$
\end{tabular}




\begin{tabular}{ll}
\multicolumn{1}{r}{ Hotter. } & \multicolumn{1}{r}{ Colder. } \\
$\mathrm{ICl}$ & $\mathrm{ICl}_{3}$ \\
$\mathrm{SnCl}_{2}$ & $\mathrm{Sn}_{2} \mathrm{Cl}_{4}$ \\
$\mathrm{GaCl}_{3}$ & $\mathrm{Ga}_{2} \mathrm{Cl}_{6}$ \\
$\mathrm{H}_{2} \mathrm{O}$ & $\mathrm{H}_{2} \mathrm{O}_{2}$ \\
$\mathrm{C}_{2} \mathrm{H}_{4} \mathrm{O}_{2}$ & $\mathrm{C}_{4} \mathrm{H}_{8} \mathrm{O}_{4}$ \\
$\mathrm{C}_{2} \mathrm{H}_{4} \mathrm{O}$ & $\mathrm{C}_{6} \mathrm{H}_{12} \mathrm{O}_{3}$
\end{tabular}

If these speculations are well founded, we ought to be able to predict the discovery of "allotropic forms" of nitrogen and the halogens. The allotropy of six of the non-metals already seems certain; most of the others are open to suspicion: chemists are naturally cautious and conservative on these fundamentals of doctrine. A dirty element may easily be called a new element or another "allotropic form." Nevertheless there are signs of surprises in store for us-dim vistas though they be. In the case of known compounds, also, there may be two metameric prussic acids, viz.

$$
\mathrm{C} \equiv \underset{\boldsymbol{a}}{\mathrm{N}}-\mathrm{H} \text { and } \mathrm{H}-\underset{\beta}{\mathrm{C}} \equiv \mathrm{N} \text {. }
$$

Calling these the alpha and beta "acids," there is some reason for thinking that it is the alpha acid which is formed during Fownes' reaction for $\mathrm{CO}$ from $\mathrm{K}_{4} \mathrm{Fe}(\mathrm{CN})_{6}$, and that probably there is hydrolysis of this $\mathrm{HCN}$, thus :-

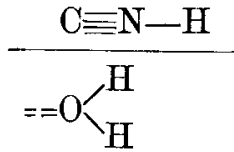

(1) Before.

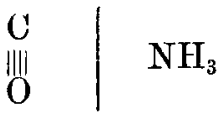

(2) After.

or
(1) Before,
$\mathrm{H}-\mathrm{N}=\mathrm{C}==$
$+\quad==\mathrm{OH}_{2}$
(2) After,
$\mathrm{H}-\mathrm{N}=\mathrm{H}_{2}$
$+\mathrm{C}=0$.

But if so, there ought surely to be some means of distinguishing the nitrile cyanide, $\stackrel{\mathrm{C}}{\mathrm{H}}=\mathrm{N}_{\mathrm{N}}$, from the imide, $\mathrm{C} \equiv \mathrm{NH}$, where the hydrogen is not directly associated with the carbon, though the problem is evidently more delicate than the discrimination of the two bodies formulated $\mathrm{C}_{2} \mathrm{H}_{5} \mathrm{CNO}$, or the two striking and odourless $\mathrm{C}_{3} \mathrm{H}_{5}$ CNS liquids now known.

The distinction to which it is here endeavoured to draw attention, between the mere raising the valency of one

Phil. Mag. S. 5. Vol. 25. No. 155. April 1888. Y 
element and the reciprocally conditional "validity" of negative or non-metallic atoms is well illustrated by the hypothesis of Friedel or Wurtz*, where Friedel's compound is given as either<smiles>C[CH]OCC</smiles>

as contrasted with the formula now proposed :-<smiles>COC=[14CH]</smiles>

where oxygen can only be tetravalent if chlorine be trivalent, and where, as it may be said, the mutual validity of the oxygen and the chlorine is really one of the points at issue.

Temperature is, then, a function of valency; and Dr. Crookes' address to the British Association served to bring out very clearly that it is also probably a periodic function $\dagger$ of the atomic weight, or at least chemical reacting weight, of an element with one alternative valency, as this paper has suggested, rather than many "alternatives" such as the hypotheses of valencies from 2 to 8 or more. The idea is well illustrated by a pendulum arrangement of the periodic series.

$$
\begin{array}{cccc|cccc}
\multicolumn{3}{c}{\text { Paramagnetic. }} & \multicolumn{4}{c}{\text { Diamagnetic. }} \\
- & { }^{\mathrm{N}} \mathrm{N}^{\prime \prime \prime} & { }^{\mathrm{v}} \mathrm{O}^{\prime \prime} & { }^{n} \mathrm{H}^{\prime} & \mathrm{Na}^{\prime} & \mathrm{Mg}^{\prime \prime} & \mathrm{Al}^{\prime \prime \prime} & + \\
+ & \mathrm{Sc}^{\prime \prime \prime} & \mathrm{Ca}^{\prime \prime} & \mathrm{K}^{\prime} & { }^{11} \mathrm{Cl}^{\prime} & { }^{1 \mathrm{v}} \mathrm{S}^{\prime \prime} & { }^{\mathrm{v}} \mathrm{P}^{\prime \prime \prime} & -
\end{array}
$$

The validity alternative valency is indicated on the left of the symbol. It will be interesting to see how future researches on the associations of vortex-rings bear upon this view. At the least it may be urged that it would be very disastrous for chemists to abandon these valence-marks, because the connexions with chemical affinity are not measurabde at this stage of the inquiry.

The alternatives of $\left(\mathrm{C}_{3} \mathrm{H}_{5}\right)^{\prime \prime \prime}$ and $\left(\mathrm{C}_{3} \mathrm{H}_{5}\right)^{\prime}$, indicated in my first paper, suggest analogies between the probable ordinary monovalent and rarer trivalent behaviour of the halogens. In some cases, also, an element may be trivalent but occasionally univalid. But they suggest the further resolution of our present chemical units. If, by way of illustration, $\left(\mathrm{C}_{3} \mathrm{H}_{5}\right)^{\prime \prime \prime}$ be represented by $(E)^{\prime \prime \prime}$, we may say we have its "allotropic

* See 'Atomic Theory,' p. 250.

$\dagger$ It is curious that the oxygen-group $0, \mathrm{~S}, \mathrm{Se}, \mathrm{Te}$ have atomic weights which are very close multiples of the oxygen atomic weight. 
forms " recognizable by the notation

\section{or even}
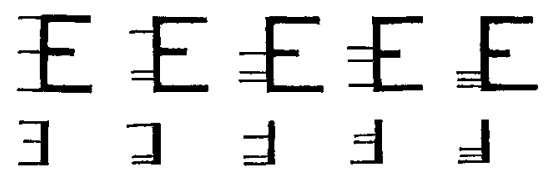

corresponding to the five trivalent groupings

$$
\mathrm{X}_{\alpha}, \quad \mathrm{X}_{\beta_{i}}, \quad \mathrm{X}_{\beta_{\mathrm{t}}}, \quad \mathrm{X}_{\beta_{\mathrm{ll}}}, \quad \mathrm{X}_{\gamma}
$$

of my previous paper. Thus we have an organic compound radical, long viewed as one of the "elements" of organic chemistry, possessing several clearly distinguished allotropic forms, as it were. On the other hand, $\mathrm{C}_{2} \mathrm{H}_{5}$ is, so far as our strong evidence goes, a genuine organic "element" without such forms. May there not be some analogous mystery in the case of our present elementary radicals which has yet to be solved, and of which, perhaps, the spectroscope-as foreshadowed by the almost uncanny researches of Dr. Crookes and Prof. Norman Lockyer-already gives us indications? * Thus Prof. Nordenskiold's experiments indicate that the crude mixture of yttria, erbia, ytterbia, \&c., which Dr. Crookes briefly calls gadolinia, has a constant molecular weight, just as $\mathrm{X}_{\alpha}, \mathrm{X}_{\beta}, \mathrm{X}_{\gamma}$ has. Yet the oxide of gadolinium is known to be the oxide of a non-simple body. Meanwhile there is surely enough to cause us to hope for the further great future of what seems to be to some the untenable, if not exploded, theory of valency.

Oxford, 28th January, 1888.

\section{POSTSCRIPT.}

The importance and difficulties of this subject of validity is seen by Professor Lothar Meyer devoting over fifty pages to it in his 'Modern Theories,' which I have, since writing my two papers, re-read with deep interest after several years' interval. It may be convenient to note briefly our chief differences of opinion.

(1) Oxygen is, as usual, taken as strictly divalent. The result appears to be that chlorine is not only mono- and trivalent, but "probably heptavalent with regard to negative

* Remembering that oxygen is characterized above all other elements by its extreme chemical sociability for others, it is noteworthy that if we add its atomic weight to the atom-weights of the soven elements of the first period, we obtain those of the second period! 
elements such as oxygen." On the other hand, the view that in the so-called molecular formula $\mathrm{KCl}$ the elements are only "apparently monovalent" leads the Professor to favour the view of metallic linkings, each metallic atom being associated with strictly monovalent chlorine atoms. Thus formulæ such as<smiles>Cl[Pb]1[Pb](Cl)[Pb](Cl)([Ge](Cl)(Cl)[Z](Cl)(Cl)Cl)[R17]1(Cl)Cl</smiles>

are quoted as probable or possible, pending vapour-density determinations. In face of the scanty evidence for di-metallic linkings in most cases, and in view of the much stronger evidence in favour of trivalent chlorine, I hold at present that the formula $\mathrm{Fe}<\underset{\mathrm{Cl}=\mathrm{Cl}}{\mathrm{Cl}=\mathrm{Cl}}>\mathrm{Fe}$ is preferable. Moreover the $\mathrm{K}_{3} \mathrm{Cl}_{3}$ formula seems less probable after the recent vapour-density determination favouring the gas molecule $\overline{\mathrm{KI}}$. The $\mathrm{Ag}-\mathrm{Ag}$ linking is at least premature.

(2) Professor Meyer so thoroughly argues for trivalent aluminium except in $\mathrm{Al}_{2} \mathrm{Cl}_{6}$, that only the acceptance of this exception to prove the rule as $\mathrm{Al}-\mathrm{Cl}=\mathrm{Cl}=\mathrm{Cl}-\mathrm{Al}$ is required. It is only in the case of hydrocarbon compounds that the strict monovalence of chlorine can be said to be demonstrated.

(3) Professor Meyer thinks that Ba \&c. are divalent in only their more common and most stable compounds, but that " the peroxides indicate a higher valency," presumably $\mathrm{Ba}^{1 v} \mathrm{O}_{2}$. $\mathrm{He}$ quotes Geuther as viewing $\mathrm{Be}, \mathrm{Mg}, \mathrm{Ca}, \mathrm{Sr}, \mathrm{Ba}$ as having valencies $2,4,6,8$, and 10 . If once the peculiarities of the non-metals in these molecular compounds are recognized, these extraordinary valence powers will disappear. It gives no explanation of the "molecular compounds" which even the "uncommon" compounds with higher valencies themselves form.

(4) The atoms $\mathrm{Ru}$ and $\mathrm{Os}$ are viewed as "undoubtedly octovalent" in their volatile oxides $\mathrm{M}^{\mathrm{rn}} \mathrm{O}_{4}$, and cobalt probably in the purpureo-chloride $\left(\mathrm{NH}_{3}\right)_{5} \mathrm{CoCl}_{3}$, as if from $\mathrm{H}_{5} \mathrm{Co}_{0}$ " $\mathrm{Cl}_{3}$. The valence numbers are "probably from 1 to $8 . "$

(5) In $\mathrm{As}_{4} \mathrm{O}_{6}$ Professor Meyer does not link arsenic with arsenic atoms, but suggests, with probability, a symmetrical arrangement:-

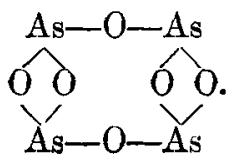


Another formula seems also probable, and indicates better what may be called the line of least resistance in the molecule in the quadrivalid or tetravalent oxygen

$$
\begin{aligned}
& \mathrm{O}=\mathrm{As} \\
& \mathrm{O}=\mathrm{As}
\end{aligned}>0 \Rightarrow=0<\begin{aligned}
& \mathrm{As}=0 \\
& \mathrm{As}=0
\end{aligned} .
$$

The Professor also states quite clearly his opinion that valency is a whole number; and it is pleasing to quote that, in pointing out that chemists were investigating relations of constitution and atomic linking formerly regarded as subjects which could never be properly investigated, he adds:- "At the present time we consider this research difficult, but we have numerous proofs in the results which we have already gained that it is not only capable of solution, but that it also affords a very fruitful field for the spirit of investigation." It is to hoped that some of the remarkable compounds discussed in these papers will be carefully and minutely examined-J.F.H.

XL. The Application of Hydraulic Power to Mercurial Pumps. By Frederick J. Smith, M.A., Millard Lecturer, Trinity College, Oxford*.

T $\mathrm{N}$ the mercurial pump of the Töpler type, a cistern of 1 mercury has to be lifted periodically through about four feet. In a form of mercurial pump of this family, devised by the author of the paper, the receiver of the pump has been made very large in comparison with the vessel to be exhausted, in order that the time of exhausting may be diminished as much as possible. The large size of the receiver, holding, as it does, nearly $40 \mathrm{lb}$. of mercury, increased the utility of the pump greatly, while it added much to the labour of working it. In order to reduce all manual labour to a minimum, the pump has been made self-acting by the addition of an hydraulic motor, having a 4 -foot stroke, controlled by a side-valve similar to the $D$-valve of a steam-engine : this valve is actuated by an auxiliary motor and valve, acted on by a projection from the end of the main piston. The figure shows the disposition of the pump and motor : the motion is quite smooth, and suitable for the work to be done, the motion at the end of the stroke being automatically checked. The cylinder is made of thickdrawn brass tube, the flange being brazed on.

Description of figure :- $\mathrm{A}$ is the cylinder, $\mathrm{H}$ the valves, $\mathrm{K}$ the inlet of the water. The cistern of mercury is attached

* Communicated by the Author ; being abstract of a paper read before the Ashmolean Society, Oxford. 